\title{
Molecular Analysis of the Bare Lymphocyte Syndrome
}

\author{
Kate E. Sullivan, John D. Stobo, and B. Matija Peterlin \\ Howard Hughes Medical Institute, and Department of Medicine, University of California, San Francisco, California 94143
}

\begin{abstract}
The bare lymphocyte syndrome is a disorder in which class I histocompatibility antigens fail to be expressed normally on the surface of lymphocytes. Utilizing complementary DNA probes for both $\beta_{2}$-microglobulin and class I genes, the molecular basis for this syndrome was investigated in a family with two siblings exhibiting the bare lymphocyte syndrome. Southern blot analysis demonstrated no gross internal defect in either class $I$ or $\beta_{2}$-microglobulin genes. Northern blot analysis of class $I$ and $\beta_{2}$-microglobulin messenger RNAs also revealed no qualitative difference between affected and unaffected family members. In contrast, quantitation of both class $I$ and $\beta_{2}$ microglobulin transcripts demonstrated each to be decreased in patients when compared to controls. Moreover, the decrease in both transcripts was coordinate. These results suggest that the bare lymphocyte syndrome may represent a pretranslational regulatory defect of both class $I$ and $\beta_{2}$-microglobulin gene expression.
\end{abstract}

\section{Introduction}

The bare lymphocyte syndrome is defined as a syndrome in which a patient's lymphocytes cannot be tissue-typed by standard serologic cytotoxicity tests. Touraine et al. (1) described a child presenting with severe combined immunodeficiency in the initial case report of 1978. Since then, several forms of the syndrome have been identified. A defect in class I major histocompatibility antigen expression has been described with and without concomitant severe combined immunodeficiency (2-7). Several case reports of a class II major histocompatibility defect have appeared recently. This class II defect may be isolated (8) or associated with a defect in class I expression (9$11)$ and has a variable phenotype. We have previously described two siblings without immunodeficiency who exhibit the bare lymphocyte syndrome. The older affected child presented in 1980 with aplastic anemia but had normal IgA, IgG, and IgM levels. The younger affected child has been healthy. Neither has suffered from any opportunistic infections nor an unusual number of viral infections (7). Analysis of these patients may help clarify the factors involved in the regulation of cell surface expression of class I antigens and may contribute to our understanding of class I antigen functions. Here, for the first

This work was presented in part at the American Association of Physicians meeting, Washington, DC, in May 1984.

Ms. Sullivan is a Medical Scientist Training Program student at the University of California, San Francisco Medical Center; Dr. Peterlin is an assistant and Dr. Stobo is an investigator with the Howard Hughes Medical Institute.

Received for publication 30 May 1984 and in revised form 19 March 1985.

J. Clin. Invest.

(c) The American Society for Clinical Investigation, Inc.

0021-9738/85/07/0075/05 \$1.00

Volume 76 , July $1985,75-79$ time is a demonstration of a pretranslational defect in both class $I$ and $\beta_{2}$-microglobulin gene expression associated with the bare lymphocyte syndrome.

\section{Methods}

Cells. Family "L," previously described (7), was used as the sole source of "bare lymphocytes" for the experiments described. An affected child (AC2; see Fig. 1) was identified during routine tissue typing in consideration for bone marrow transplant as treatment for aplastic anemia. At that time, another affected child (AC4) was also identified as having the bare lymphocyte syndrome. Fresh peripheral blood mononuclear cells (PBMCs), ${ }^{1}$ consisting of lymphocytes and monocytes, were isolated through a Ficoll-Hypaque gradient. Fresh circulating leukocytes (lymphocytes, monocytes, and granulocytes) were isolated in $1.5 \%$ dextran (200,000 mol wt). Epstein-Barr virus (EBV)-transformed lymphocytes from the family members were continuously maintained in RPMI 1640 supplemented with $10 \%$ fetal calf serum and the usual antibiotics.

Northern and RNA dot blot analysis. Three probes were utilized in these analyses. The $\beta_{2}$-microglobulin probe (gift of $\mathrm{K}$. Itakura) is a 550-base-pair (bp) complementary (c) DNA clone (12). The class I probe (gift of S. Weissman) is homologous to HLA B7 but crosshybridizes to HLA-A, -B, and -C genes (13). The actin probe is a 1.5kilobase (kb) cDNA clone (gift of P. Gunning) (14). The gift of ribosomal cDNA was generated from L cells by Andree Dozy. RNA was isolated by the guanidinium method (15). For the Northern blot in Fig. 2-C, $25 \mu \mathrm{g}$ of total RNA was isolated from the EBV-transformed lines, denatured in formaldehyde as previously described $(16,17)$, and applied to a $0.8 \%$ agarose gel. For the Northern blot in Fig. 5, $5 \mu \mathrm{g}$ of total RNA isolated from PBMCs was used. The gel was photographed using a silica thin-layer chromatography plate to identify the positions of the $18 \mathrm{~S}$ and $28 \mathrm{~S}$ bands. Blots were baked and incubated with a $50 \%$ formamide solution at $42^{\circ} \mathrm{C}$, as previously described (17). $50 \mathrm{ng}$ of probe, nick-translated to a specific activity of $10^{8} \mathrm{cpm} / \mu \mathrm{g}$ was denatured by boiling and added to $10 \mathrm{ml}$ of fresh formamide solution. After 24 h of incubation the blots were washed in $0.1 \times$ standard saline citrate (pH 7.0), $0.1 \%$ sodium dodecyl sulfate (SDS) at $55^{\circ} \mathrm{C}$ as previously described (17). Northern dot blots utilized total RNA isolated as above from leukocytes. For the dot blots, $1 \mu \mathrm{g}$ of RNA was denatured as above. Twofold dilutions of RNA were made into microtiter wells with 20-strength SSC. The RNA was then applied to nitrocellulose and probed as above.

Fluorescent analysis. Three antibodies from Becton-Dickinson \& Co. (Mountain View, CA) were used in the identification of subpopulations of PBMC. Leu 1 (clone L17F12) depicts most $T$ cells (18). HLA-D-related (DR) (clone L243)-specific antibody binds nonpolymorphic regions of class II molecules (19). The M3 (clone M $\phi$ P9) antibody is specific for 70-90\% of mature forms of circulating monocytes (20). These three antibodies are linked to phycoerythrin, which emits at a wavelength distinct from that of fluorescein isothiocyanate (FITC) and allows simultaneous two-color analysis (21). Two other antibodies were used to analyze the display of class I antigens on the surface of PBMC. Anti- $\beta_{2}$-microglobulin (clone L368) linked to FITC was purchased from Becton-Dickinson \& Co. (19). W6/32 is a monoclonal antibody that recognizes a nonpolymorphic determinant on class $I$

1. Abbreviations used in this paper: EBV, Epstein-Barr virus; FITC, fluorescein isothiocyanate; PBMC, peripheral blood mononuclear cell(s). 
Father

a A2 Cw4 Bw35 Bw6 DR3

b A2 C- Bw44 Bw4 DR4

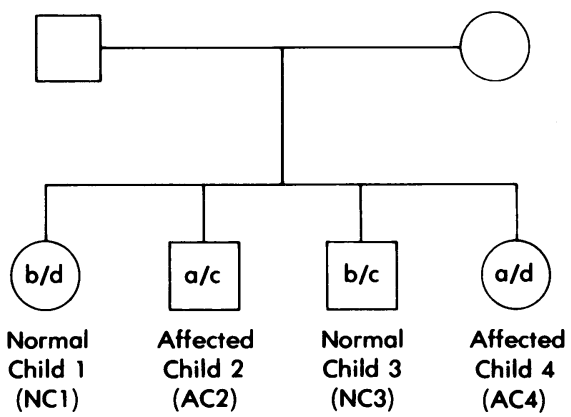

Figure 1. Pedigree. Family "L" consists of the unaffected mother $(M)$ and father $(F)$, two unaffected children $(N C 1, N C 3)$, and two affected children $(A C 2, A C 4)$.

molecules (22). Fluorescent analysis using W6/32 was performed using an indirect immunofluorescent technique. Flow cytometry was performed on a FACS IV (Becton-Dickinson \& Co.) as previously described. $(21,23)$.

\section{Results}

To examine the structure of the class I and the $\beta_{2}$-microglobulin genes, Southern blots were prepared from DNA isolated from the family members' PBMCs. Southern blot analysis demonstrated no gross internal rearrangements or deletions in either the class I genes or the $\beta_{2}$-microglobulin genes of the affected children when compared to the normal siblings or the parents (data not shown and reference 7). In an effort to analyze the transcripts from these genes, RNA was isolated from the EBVtransformed cells of the family. Six weeks after EBV transformation, "bare lymphocytes" have been found to have normal class I surface expression $(5,7)$. Hybridization of Northern blots with the $\beta_{2}$-microglobulin probe revealed bands $\sim 1 \mathrm{~kb}$ in length for all family members (Fig. 2). There was no qualitative difference between the affected and the unaffected family members. When the Northern blots were hybridized with the B7 probe, specific for class I antigens, a single band

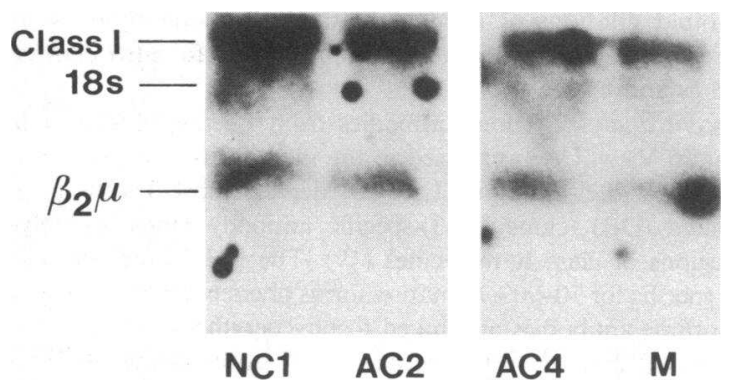

Figure 2. Northern blot of transcripts isolated from EBV-transformed cells of family "L." 25- $\mu$ g samples of total RNA were electrophoresed on a Northern formaldehyde gel to assess transcript length differences in the affected children. Shown in this figure are bands hybridizing with class I and $\beta_{2}$-microglobulin $\left(\beta_{2} \mu\right)$ specific probes for two unaffected family members $(M, N C I)$ and two affected family members $(A C 2, A C 4)$. There are no apparent differences in transcript length when affected are compared with unaffected family members. $\sim 1.7 \mathrm{~kb}$ in length was found for all family members (Fig. 2). Therefore, it appears that neither the genes nor the transcripts for class I and $\beta_{2}$-microglobulin are qualitatively abnormal in the bare lymphocyte syndrome.

Quantitative analysis by Northern dot blots was undertaken in order to evaluate the levels of class $I$ and $\beta_{2}$-microglobulin transcripts in the circulating leukocytes from the affected and unaffected family members. $1 \mu \mathrm{g}$ of total RNA isolated from the leukocytes of the family members was dotted onto nitrocellulose. This dot blot was then hybridized with either the class I, $\beta_{2}$-microglobulin, or an actin control probe (Fig. 3). Class I and $\beta_{2}$-microglobulin transcripts were found to be much lower by densitometry in the affected children than in the unaffected family members. Actin transcripts were only slightly decreased. Thus, the bare lymphocyte syndrome is associated with a quantitative defect in the number of class I and $\beta_{2}$-microglobulin transcripts.

Decreased levels of RNAs specific for class I and $\beta_{2}$ microglobulin could indicate a general diminution among all cells or represent the averaging of different levels among subpopulations of cells. The density of class I antigens on subpopulations of mononuclear cells was analyzed by flow cytometry. PBMCs from the affected family members stained with either anti-class $I$ or anti- $\beta_{2}$-microglobulin monoclonal antibodies exhibited a density of each molecule that was 10$25 \%$ of that seen in unaffected family members or unrelated controls. Class $I$ and $\beta_{2}$-microglobulin staining on platelets identified by forward light scatter demonstrated no difference between affected and unaffected family members (data not shown). Specific subpopulations of cells were identified by means of phycoerythrin-labeled antibodies (i.e., phycoerythrin Leu 1, phycoerythrin DR, and phycoerythrin M3), and the relative class $I$ and $\beta_{2}$-microglobulin density on the cells of each subpopulation was determined by using FITC-linked antibodies (Fig. 4). In an affected child, class I and $\beta_{2^{-}}$ microglobulin-specific fluorescence associated with the $T$ cell

\section{F NC1 AC2 AC4}
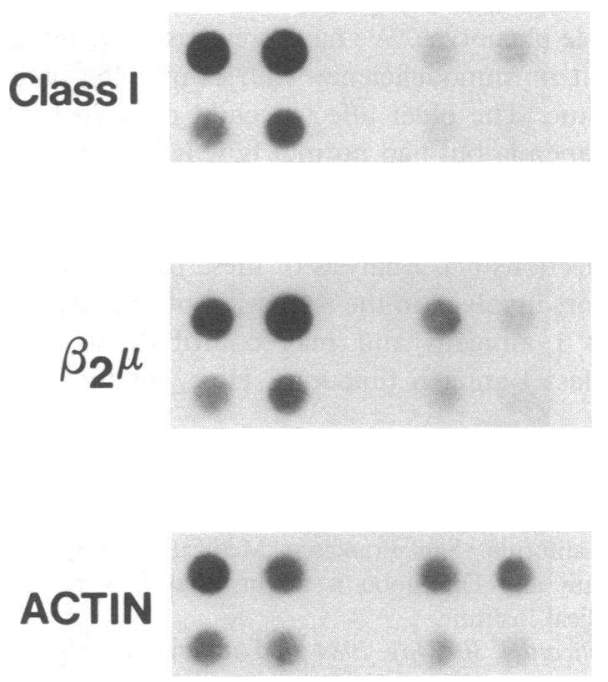

Figure 3. Quantitative analysis of class I and $\beta_{2}$-microglobulin transcripts. RNA was isolated as described from circulating leukocytes and dotted onto nitrocellulose in twofold dilutions of $1 \mu \mathrm{g}$ of RNA. This blot was probed with class $\mathrm{I}, \beta_{2}$-microglobulin $\left(\beta_{2} \mu\right)$, or actinspecific probes as indicated. 
population was 10.5 -fold less than the mother or an unrelated control. Staining in the DR and M3 positive population was fourfold less in the affected child than in the control (Table I).

These findings suggest that not all cells are equally affected and that RNA levels might correspond more closely to surface expression if only affected cells are analyzed. When RNA from PBMCs, consisting of lymphocytes and monocytes, are analyzed by Northern blotting and densitometric scannings normalized to ribosomal (r)RNA levels, a 10-fold decrease of class I transcripts is seen in an affected child when compared to an unaffected family member (Fig. 5). These data demonstrate that the levels of class $I$ and $\beta_{2}$-microglobulin transcripts correlate directly with the cell surface expression of these antigens. However, RNA dot blots revealed that class I and $\beta_{2}$-microglobulin transcripts are only threefold decreased in leukocytes, consisting of granulocytes in addition to lymphocytes and monocytes. This suggests that class $I$ and $\beta_{2}$-microglobulin expression is not diminished in all circulating cells and that patients granulocytes may in fact have normal class I and $\beta_{2}$-microglobulin transcript levels.

\section{Discussion}

These experiments have demonstrated a pretranslational defect in class $I$ and $\beta_{2}$-microglobulin expression. This defect is differentially expressed in different subpopulations of cells and it is possible that only mononuclear cells are affected. When class I and $\beta_{2}$-microglobulin transcript levels are analyzed from total leukocytes they are found to be approximately threefold decreased. Mononuclear cell transcripts, on the other hand, are 10-fold decreased in the affected children. This suggests granulocyte expression may be normal in these children. Platelet expression was found to be normal and others have reported normal class I surface expression on fibroblasts, granulocytes, and platelets $(1-6,24)$.

Both class I and $\beta_{2}$-microglobulin-specific transcripts were found to be decreased in the mononuclear cells of these affected children. Because these genes reside on chromosomes 6 and 15, respectively, and because EBV reverses the defect, it is unlikely that mutations in either gene could account for
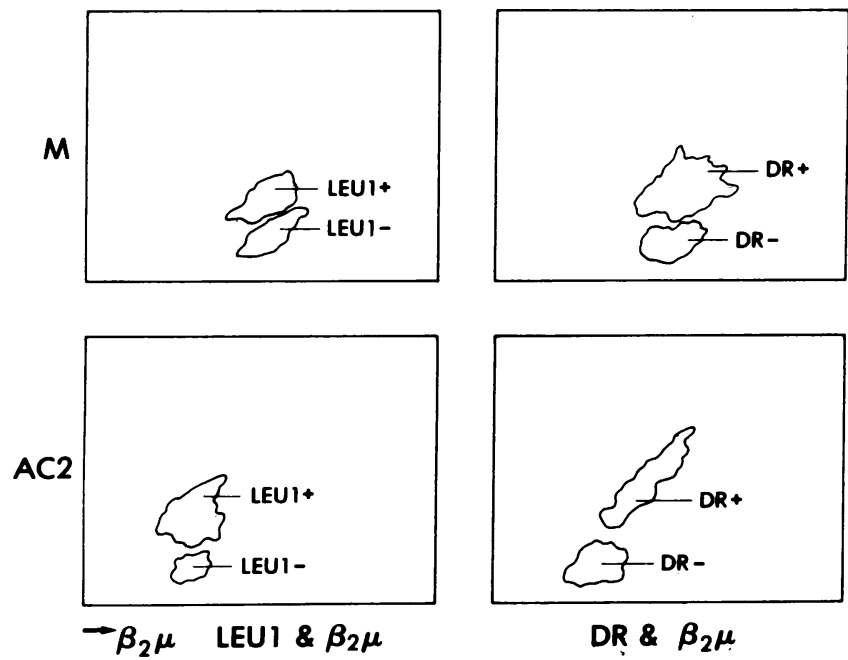

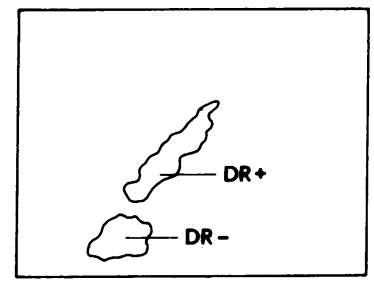

DR \& $\boldsymbol{\beta}_{\mathbf{2}} \boldsymbol{\mu}$
Table I. Peak Fluorescence Intensity for PBMC Subpopulations

\begin{tabular}{lrrr}
\hline & \multicolumn{3}{c}{ Cell surface molecule detected } \\
\cline { 2 - 4 } Source & Leu 1 & DR & M3 \\
\hline Unrelated control & 112 & 110 & 105 \\
Mother & 89 & 85 & 89 \\
AC2 & 8 & 22 & 24
\end{tabular}

In this table, values are given for the intensity of fluorescence corresponding to the $\beta_{2}$-microglobulin staining. Different subpopulations of cells were detected with a counterstain. Leu 1 depicts most $T$ cells, DR depicts $B$ cells and monocytes, and M3 depicts mature monocytes. Here, the intensity of $\beta_{2}$-microglobulin staining in the Leu 1 population can be seen to be much less in the affected child (AC 2) than in the mother (M). After normalization of peak channel values to background, values were converted from the logarithmic scale using the formula, $10^{x / 57}=$ fluorescence intensity $(x=$ peak channel value). Thus, in the Leu 1 population, the affected child's cells express only one-tenth the density of $\beta_{2}$-microglobulin as the mother. In the DR + and M3 population, the affected child's cells express approximately fourfold less $\beta_{2}$-microglobulin than the unaffected mother.

our findings. Instead, it is likely that the bare lymphocyte syndrome represents a defect in the regulation of class $I$ and $\beta_{2}$-microglobulin gene expression. A related syndrome with a class II defect is also thought to represent a defect in regulation (9).

That these genes share common regulatory pathways is suggested by the finding that they are coordinately expressed in development. Class $I$ and $\beta_{2}$-microglobulin antigens are absent from fertilized mouse eggs but appear later in development $(25,26)$. This developmental control is reproduced in embryonal carcinoma cells (27). Embryonal carcinoma cells do not express class I antigens on their surface nor do they have detectable levels of transcript for either gene (28-30). Differentiation of these cells is accompanied by coordinate accumulation of messenger RNAs and surface expression of class I molecules (27). From these experiments, it is clear that class $I$ and $\beta_{2}$ microglobulin genes are simultaneously induced during development.

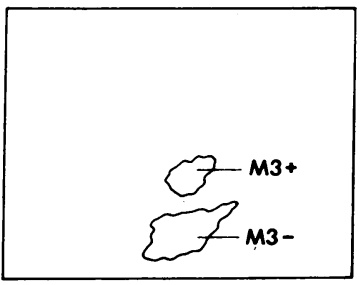

Figure 4. Two-color fluorescent cytometry analysis of $\beta_{2}$-microglobulin expression on PBMC subsets. This figure compares $\beta_{2}$-microglobulin staining of an unaffected family member's PBMC subsets $(M)$ and those of an affected family member $(A C 2)$. The vertical axis depicts staining with either Leu 1, anti-DR, or M3 as indicated. Therefore, subsets are separated on the vertical axis, with the uppermost population staining positive with the indicated antibody. Notice that the intensity of flourescence in the vertical axis is normal in the affected child; demonstrating that Leu 1, DR, and M3 expression is normal on "bare lymphocytes." The horizontal axis depicts staining with anti- $\beta_{2}$-micro-

globulin. All subsets in the affected children exhibit decreased staining with anti- $\beta_{2}$-microglobulin with the greatest decrease apparent in $T$ cells depicted by Leu 1. This is quantified in Table I. 


\section{DENSITOMETRY ANALYSIS}

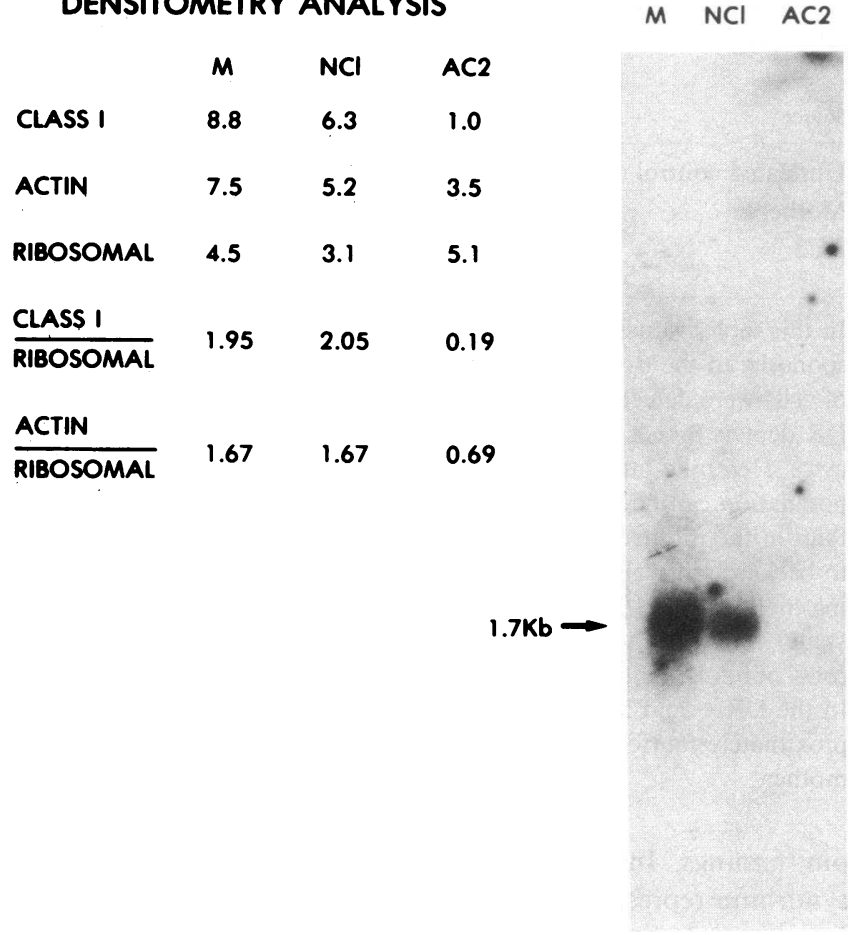

Figure 5. Northern blot and densitometry of transcripts isolated from the PBMCs (lymphocytes and monocytes) of three family members. Shown in this figure are bands hybridizing to the class I-specific probe from two unaffected family members $(M$ and $N C l)$ and one affected family member $(A C 2)$. Class I-specific transcripts are 10-fold less abundant in the affected child when normalized to ribosomal RNA levels. The densitometry table also reveals a slight decrease in actin transcript levels in the affected child. Notice the apparent difference in $\mathrm{M}$ and $\mathrm{NCl}$ class I levels disappears when densitometry levels are normalized to correct for loading error.

Experiments investigating the regulation of expression of class I and $\beta_{2}$-microglobulin genes in a mature, expressing cell, also suggest that class $I$ and $\beta_{2}$-microglobulin genes share common regulatory pathways. Lymphoblastoid and melanoma cell lines as well as PBMCs have been induced to increase their class $I$ and $\beta_{2}$-microglobulin surface expression after administration of interferon (31-33). It is not known which sequences are responsible for the regulation of class I transcription. In transfection experiments, interferon was shown to increase the expression of the introduced HLA B7 genes irrespective of deletions in the $5^{\prime}$ flanking region and the first exon $(34,35)$.

These experiments suggest that class I and $\beta_{2}$-microglobulin genes share common regulatory pathways. The bare lymphocyte syndrome could represent a defect at some step leading to coordinate gene expression. First, it could represent an abnormality in the production of lymphokines (e.g., interferon) known to increase class I and $\beta_{2}$-microglobulin expression. In two studies, patients with a defect in expression of both class I and class II molecules, $\alpha$-interferon was able to restore class I expression $(4,36)$. Addition of $\alpha$-interferon to the cells of one of our patients failed to reverse the defect (data not presented), suggesting that the defect is not simply due to decreased production of $\alpha$-interferon. Second, a synthetic or structural abnormality in the $\alpha$ - or $\beta$-interferon receptor could make "bare lymphocytes" refractory to those lymphokines.
We have no data to address this issue. Third, intracellular effector molecules such as DNA binding proteins that recognize regulatory sites flanking the class I and $\beta_{2}$-microglobulin genes and serve to modify their gene expression may be defective. If tissue-specific regulators of transcription are shared between these genes, one could postulate a lesion in a single protein that binds those specific DNA sequences. Trans- acting regulatory factors have been postulated for class II histocompatibility genes (37), and it is possible that they exist for class I histocompatibility genes. The low levels of class I and $\beta_{2}$ microglobulin transcripts, which are found in the lymphocytes of our patients, may be products of a constitutive pathway unaffected by the absence of a regulatory protein. This constitutive pathway may also account for the normal levels of class I and $\beta_{2}$-microglobulin found on our patients platelets.

The levels of class I and $\beta_{2}$ microglobulin transcripts in the bare lymphocytes were $\sim 10$-fold lower than in normal controls. The levels of surface class I molecules were from 4to 10-fold diminished when affected and unaffected family members were compared. Actin levels were slightly decreased compared to controls and this may reflect altered metabolism in these cells. Therefore, a pretranslational defect in class I and $\beta_{2}$-microglobulin certainly constitutes a major factor in the bare lymphocyte syndrome, but at this time we are not able to rule out other effects. It should be stressed that the defect observed in this family with the bare lymphocyte syndrome without immunodeficiency may not reflect that found in other cases of the bare lymphocyte syndrome with immunodeficiency. Only through further study of this and similar disorders will the true nature of the bare lymphocyte syndrome defect be revealed and therapeutic intervention become possible.

\section{Acknowledgments}

We gratefully acknowledge the cooperation of the " $L$ " Family in these studies. Contributions of probes by Dr. Itakura (City of Hope Research Institute), Dr. Weissman (Yale University School of Medicine), Dr. Gunning (Stanford University School of Medicine), and Andree Dozy of our institution are also acknowledged. Flow cytometry was performed on the Howard Hughes Medical Institute FACS IV with the technical assistance of Ms. Araxy Missirian-Bastian.

This work was support in part by The Council for Tobacco Research grant no. 1593, U. S. Public Health Service grant 5R01 AI14104, and National Institutes of Health National Institute of General Medical Services training grant GMO 7618.

\section{References}

1. Touraine, J. L., H. Betuel, G. Souillet, and M. Jeune. 1978. Combined immunodeficiency disease associated with absence of cell surface HLA-A and -B. Lancet. I:319-320.

2. Touraine, J. L. 1981. The bare lymphocyte syndrome: report on the registry antigens. J. Pediatr. 93:47-51.

3. Touraine, J. L., H. Betuel, F. Touraine, N. Philippe, B. Betend, and R. Francois. 1980. Role of MHC determinants in immunodeficiency diseases as shown by the "bare lymphocyte syndrome" and by chimeric patients. INSERM (Inst. Natl. Santé Rech. Méd.) Symp. 16:79-86.

4. Schuurman, R. K. B., E. W. Gelfand, J. L. Touraine, and J. J. Van Rood. 1980. Lymphocyte abnormalities associated with primary immunodeficiency disease. INSERM (Inst. Natl. Santé Rech. Méd.) Symp. 16:87-99.

5. Touraine, J. L., and H. Betuel. 1981. Immunodeficiency diseases and the expression of HLA antigens. Hum. Immunol. 2:147-153.

6. Schuurman, R. K. B., J. J. Van Rood, J. M. Vossen, P. T. A. Schellekens, T. M. Feltkamp-Vroom, E. Doyer, F. Gmelig- 
Meyling, and H. K. A. Visser. 1979. Failure of lymphocyte membrane HLA-A and -B expression in two siblings with combined immunodeficiency. Clin. Immunol. Immunopathol. 14:418-434.

7. Payne, R., F. Brodsky, B. M. Peterlin, and L. M. Young. 1983. "Bare lymphocytes" without immunodeficiency. Hum. Immunol. 6: 219-227.

8. Hadam, M. R., R. Dopfer, H. H. Peter, and D. Niethammer. 1984. Congenital agammaglobulinemia associated with lack of expression of HLA D region antigens. Proceedings of the European Group for Immunodeficiencies, Chateau De Fillerval, France. March 29-31. In press.

9. Lisowska-Grospierre, B., D. J. Charron, C. de Préval, A. Durandy, C. Griscelli, and B. Mach. 1985. A defect in the regulation of major histocompatibility complex class II gene expression in human HLADR negative lymphocytes from patients with combined immunodeficiency syndrome. J. Clin. Invest. 76:381-385.

10. Zegers, B. J. M., C. J. Heijnen, J. J. Roord, W. Kuis, R. K. B. Schuurman, J. M. Stoop, and R. E. Ballieux. 1983. Defective expression of mononuclear cell membrane HLA antigens associated with combined immunodeficiency: impaired cellular interactions. Birth Defects. 19: 93-96.

11. Liswska-Grospierre, B., A. Durandy, J. L. Virelizier, A. Fischer, and C. Griscelli. 1983. Combined immunodeficiency with defective expression of HLA: modulation of an abnormal HLA synthesis and functional studies. Birth Defects. 19:93-96.

12. Suggs, S., R. B. Wallace, T. Hirose, E. H. Kawashima, and K. Itakura. 1981. Use of synthetic oligonucleotides as hybridization probes: isolation of cloned cDNA sequences for human $\beta_{2}$ microglobulin. Proc. Natl. Acad. Sci. USA. 78:6613-6617.

13. Sood, A. K., D. Periera, and S. Weissman. 1981. Isolation and partial nucleotide sequence of a cDNA clone for human histocompatability antigen HLA-B by use of an oligodeoxynucleotide primer. Proc. Natl. Acad. Sci. USA. 78:616-620.

14. Gunning, P., P. Ponte, H. Okayama, J. Engel, H. Blau, and L. Kedes. 1983. Isolation of full length cDNA clones for human $\alpha, \beta$ and $\gamma$ actin mRNAs: skeletal but not cytoplasmic actins have an amino terminal cystein that is subsequently removed. Mol. Cell. Biol. 3:787795.

15. Chirgwin, J. M., A. E. Przybyla, R. J. MacDonald, and W. J. Rutter. 1979. Isolation of biologically active ribonucleic acid from sources enriched in ribonuclease. Biochemistry. 18:5294-5299.

16. Goldberg, D. A. 1980. Isolation and partial characterization of the Drosophila alcohol dehydrogenase gene. Proc. Natl. Acad. Sci. USA. 77:5794-5798.

17. Maniatis, T., E. F. Fritsch, and J. Sambrook. 1982. Molecular Cloning. Cold Spring Harbor Laboratory, Cold Spring Harbor, NY. 187-363.

18. Engleman, E. G., R. Warnke, R. I. Fox, and R. Levy. 1981. Studies of human $\mathrm{T}$ lymphocyte antigen recognized by a monoclonal antibody. Proc. Natl. Acad. Sci. USA. 78:1791-1795.

19. Lampson, L. A., and R. Levy. 1980. Two populations of Ialike molecules on a human B cell line. J. Immunol. 125:293-300.

20. Dimitriu-Bona, A., G. R. Burmester, S. J. Waters, and R. J. Winchester. 1983. Human mononuclear phagocyte differentiation antigens. I. Patterns of antigenic expression on the surface of human monocytes and macrophages defined by monoclonal antibodies. $J$. Immunol. 130:145-152.

21. Oi, V. T., A. N. Glazer, and L. Stryer. 1982. Flourescent phycobiliprotein conjugates for analysis of cells and molecules. J. Cell Biol. 93:981-986.

22. Barnstable, C. J., W. F. Bodmenr, G. Brown, G. Galfre, C. Milstein, A. F. Williams, and A. Ziegler. 1978. Production of monoclonal antibodies to group A erythrocytes, HLA and other human cell surface antigens-new tools for genetic analysis. Cell. 14:9-20.

23. Gonwa, T., and J. D. Stobo. 1984. Differential expression of Ia molecules by human Monocytes. J. Clin. Invest. 74:859-866.

24. Kuis, W., J. Roord, B. J. M. Zegers, R. K. B. Schuurman, C. J. Heijnen, W. M. Baldwin, E. Goulmy, F. Claas, R. J. van de Griend, G. T. Rijkers, J. J. van Rood, J. M. Vossen, R. E. Balliieux, and J. W. Stoop. 1981. Clinical and immunological studies in a patient with the "bare lymphocyte" syndrome. Bone Marrow Transplant. Eur. 2:201-208.

25. Buc-Caron, M. H., H. Condamine, and F. Jacob. 1978. The presence of F9 antigen on the surface of mouse embryonic cells until day 8 of embryogenesis. J. Embryol. Exp. Morphol. 47:149-160.

26. Sawicki, J. A., T. Magnuson, and C. J. Epstein. 1981. Evidence for expression of the paternal genome in the two cell mouse embryo. Nature (Lond.) 294:450-451.

27. Gachelin, G. 1978. The Cell surface antigens of mouse embryonal carcinoma cells. Biochim. Biophys. Acta. 516:27-60.

28. Morello, D. 1978. Absence of reaction of a xenogenic anti-H2 serum with mouse embryonal carcinoma cells. Transplantation (Baltimore). 26:119-125.

29. Morello, D., F. Daniel, P. Baldacci, Y. Cayre, G. Gachelin, and $P$. Kourilsky. 1982. Absence of significant $\mathrm{H}-2$ and $\beta_{2}$ microglobulin mRNA expression by mouse embryonal carcinoma cells. Nature (Lond.) 296:260-262.

30. Croce, C. M., A. Linnenbach, K. Hebner, J. R. Parnes, D. H. Margulies, E. Appella, and J. G. Seidman. 1981. Control of expression of histocompatability antigens $(\mathrm{H}-2)$ and $\beta_{2}$ microglobulin in $\mathrm{F9}$ teratocarcinoma stem cells. Proc. Natl. Acad. Sci. USA. 78:5754-5758.

31. Burrone, O. R., and C. Milstein. 1982. Control of HLA- A,B,C synthesis and expression in interferon treated cells. EMBO (Eur. Mol. Biol. Organ.) J. 1:345-349.

32. Basham, T. Y., M. F. Bourgeade, A. A. Creasey, and T. C. Merigan. 1982. Interferon increases HLA synthesis in melanoma cells: interferon resistant and sensitive cell lines. Proc. Natl. Acad. Sci. USA. 79:3265-3269.

33. Heron, I., M. Hokland, and K. Berg. 1978. Enhanced expression of $\beta_{2}$ microglobulin and HLA antigens on human lymphoid cells by interferon. Proc. Natl. Acad. Sci. USA. 75:6215-6219.

34. Yoshie, O., H. Schmidt, E. S. P. Reddy, S. Weissman, and P. Lengyel. 1982. Mouse interferons enhance the accumulation of a human HLA RNA and protein in transfected mouse and hamster cells. J. Biol. Chem. 257:13169-13172.

35. Yoshie, O., H. Schmidt, P. Lengyel, E. S. P. Reddy, W. R. Morgan, and S. M. Weissman. 1984. Transcripts of human HLA gene fragments lacking the $5^{\prime}$ terminal region in transfected mouse cells. Proc. Natl. Acad. Sci. USA. 81:649-653.

36. Durandy, A., J. L. Virelizier, and C. Griscelli. 1983. Enhancement by interferon of membrane HLA antigens in patients with combined immunodeficiency with defective HLA expression. Clin. Exp. Immunol. 52:173-178.

37. Gladstone, P., and D. Pious. 1980. Identification of a Transacting function regulating HLA-DR expression in a DR- negative $B$ cell variant. Somatic Cell Genet. 6:285-298. 